\title{
OPEN Identification of natural product modulators of Merkel cell carcinoma cell growth and survival
}

\author{
Emily A. Smith ${ }^{1,2}$, Natasha T. Hill ${ }^{3}$, Tara Gelb ${ }^{3}$, Khalid A. Garman ${ }^{3}$, Ekaterina I. Goncharova ${ }^{1,4}$, \\ Heidi R. Bokesch ${ }^{1,2}$, Chang-Kwon Kim ${ }^{1}$, Karen L. Wendt' ${ }^{5}$, Robert H. Cichewicz ${ }^{5}$, \\ Kirk R. Gustafson ${ }^{1}$, Isaac Brownell ${ }^{3}$ \& Curtis J. Henrich ${ }^{1,2 \bowtie}$
}

Merkel cell carcinoma (MCC) is a rare, but aggressive skin cancer the incidence of which has increased significantly in recent years. The majority of MCCs have incorporated Merkel cell polyomavirus (VP-MCC) while the remainder are virus-negative (VN-MCC). Although a variety of therapeutic options have shown promise in treating MCC, there remains a need for additional therapeutics as well as probes for better understanding MCC. A high-throughput screening campaign was used to assess the ability of $>25,000$ synthetic and natural product compounds as well as $>20,000$ natural product extracts to affect growth and survival of VN-MCC and VP-MCC cell lines. Sixteen active compounds were identified that have mechanisms of action reported in the literature along with a number of compounds with unknown mechanisms. Screening results with pure compounds suggest a range of potential targets for MCC including DNA damage, inhibition of DNA or protein synthesis, reactive oxygen species, and proteasome inhibition as well as NFKB inhibition while also suggesting the importance of zinc and/or copper binding. Many of the active compounds, particularly some of the natural products, have multiple reported targets suggesting that this strategy might be a particularly fruitful approach. Processing of several active natural product extracts resulted in the identification of additional MCC-active compounds. Based on these results, further investigations focused on natural products sources, particularly of fungal origin, are expected to yield further potentially useful modulators of MCC.

Merkel cell carcinoma (MCC) is a rare and aggressive neuroendocrine carcinoma of the skin ${ }^{1-3}$. MCC has histological properties that led to the initial belief that this cancer started in Merkel cells; however it is currently debated from which cell type this cancer originates ${ }^{2,3}$. MCC incidence has increased substantially in recent years ${ }^{4,5}$. Current treatment of MCC is surgery and radiation for localized tumors and immunotherapy for advanced disease ${ }^{3,6}$. Due to the highly aggressive nature of the tumors, reoccurrence is typically observed ${ }^{6}$. Immunotherapies have shown promise as a monotherapy for $\mathrm{MCC}^{1,6}$ but more effective treatments are still needed.

There are two mechanisms leading to MCC carcinogenesis: integration of the Merkel cell polymavirus (MCPyV) into the host genome or accumulation of ultraviolet light (UV) mutations. Clonal integration of MCPyV DNA into the host genome is observed in approximately $80 \%$ of MCC tumors ${ }^{3}$. The integrated viral genome invariably has a truncating mutation of the large T antigen (LT) that is hypothesized to be required for MCC pathogenesis ${ }^{3}$. The truncated LT and small T antigen (ST) are viral oncogenes expressed in virus positive MCC (VP-MCC) tumors that are potential therapeutic targets ${ }^{3}$. The remaining $20 \%$ of MCC tumors are virus negative (VN-MCC) and are associated with UV induced DNA damage leading to a high mutational burden ${ }^{3}$. Inactivation of tumor suppressor genes and activation of protooncogenes lead to possible treatable targets in major pathways involved in tumorigenesis ${ }^{1}$. Some alterations are shared between both tumor types, while others are only seen in VN-MCC tumors. Although several promising molecular targets have been suggested for therapeutic development ${ }^{7}$, not all aspects of VN-MCC and VP-MCC tumorigenesis are known. Therefore, the

\footnotetext{
${ }^{1}$ Molecular Targets Program, National Cancer Institute, Frederick, MD 21702, USA. ${ }^{2 B a s i c ~ S c i e n c e ~ P r o g r a m, ~}$ Frederick National Laboratory for Cancer Research, Frederick, MD 21702, USA. ${ }^{3}$ Dermatology Branch, National Institute of Arthritis and Musculoskeletal and Skin Diseases, Bethesda, MD 20891, USA. ${ }^{4}$ Advanced Biomedical Computational Science, Frederick National Laboratory for Cancer Research, Frederick, MD 21702, USA. ${ }^{5} \mathrm{Natural}$ Products Discovery Group, Department of Chemistry \& Biochemistry, Institute for Natural Products Applications and Research Technologies, University of Oklahoma, Norman, OK 73019, USA. ${ }^{\varpi}$ email: henrichcj@mail.nih.gov
} 
discovery of compounds that are selectively cytotoxic could provide potential effective treatments as well as provide information about novel oncodrivers for each tumor type.

A high throughput screen (HTS) was developed to discover possible selective small molecules effective against MCC. In order to simplify and speed development and screening, three cell lines were chosen as representative of VN-MCC (MCC26), VP-MCC (MKL-1) tumor types along with a non-cancerous skin cell line (HaCaT) for determination of specificity. Loss of cell viability was assessed after treatment with 27,753 pure compounds and 20,532 natural product extracts. Active samples from the initial screen were then validated across additional VN-MCC and VP-MCC cell lines. Among the active compounds identified which have known mechanisms of action, many of their targets have been shown to be important in MCC. Compounds and derivatives obtained from natural products comprise a large proportion of approved drugs, particularly for cancer, and continue to provide rich resources for drug discovery ${ }^{8,9}$. Many of the active compounds are natural products and a variety of natural products have also been previously identified as modulators of MCC cell growth and survival ${ }^{10,11}$. To further access the wide chemical diversity extant in natural products, a library consisting of both crude and partially purified natural product extracts from marine, plant, bacterial, and fungal sources was assessed. Identification of natural product extracts that affect MCC cell viability can be expected to lead to discovery of additional new compounds with potentially novel mechanisms of action.

\section{Materials and methods}

Materials. All cell culture components were from Invitrogen (Carlsbad, CA, USA). Clear 384-well tissue culture-treated assay plates were from Perkin-Elmer (Waltham, MA, USA). 2,3-bis[2-methoxy-4-nitro-5sulfophenyl]-2H-tetrazolium-5-carboxanilide (XTT) and natural products were obtained from the Drug Synthesis and Chemistry Branch, Developmental Therapeutics Program, Division of Cancer Treatment and Diagnosis, National Cancer Institute (Frederick, MD, USA). Other pure compounds were from commercial or academic chemistry sources. Natural product extracts were obtained from the Natural Products Support Group of the Developmental Therapeutics Program, Division of Cancer Treatment and Diagnosis, National Cancer Institute (Frederick, MD) and the University of Oklahoma Fungal Repository (Norman, OK). LOPAC1280 Library of Pharmacologically Active compounds was from Sigma (St. Louis, MO). Available confirmed active compounds were either obtained from the original supplier or were purchased from Sigma (St. Louis, MO). Chemical structures were rendered in ChemDraw (Perkin-Elmer, Waltham, MA).

Cell lines used. Three VN-MCC lines (MCC13 and MCC26 ${ }^{12}$, and UISO ${ }^{13}$ ), along with 3 VP-MCC cell lines $\left(\mathrm{MKL}-1^{14}, \mathrm{MKL}-2^{15}\right.$, and $\left.\mathrm{WaGa}^{16}\right)$ as well as HaCaT immortalized keratinocytes ${ }^{17}$ were used.

Differential growth inhibition/cytotoxicity assay. VN-MCC and VP-MCC cell lines were maintained in RPMI supplemented with 10\% fetal bovine serum and penicillin-streptomycin. The control cell line, HaCaT, was maintained in DMEM supplemented with $10 \%$ fetal bovine serum and $1 \%$ penicillin-streptomycin. Adherent subconfluent cells (HaCaT, MCC13, MCC26, UISO) were harvested by trypsinization and resuspended in the same medium. The non-adherent cell lines (MKL-1, MKL-2, WaGa) were treated with Accutase and passed through a cell strainer to establish a single cell solution suspension. Cells were counted, then transferred to 384well tissue culture-treated plates ( $45 \mu \mathrm{L}$ per well) using a $\mu$ Fill microplate liquid dispenser (BioTek, Winooski, VT, USA). Cells were incubated for $4 \mathrm{~h}$ before treatment with test or control samples (prediluted to $10 \times$ final concentration in RPMI). For primary screening, cell viability was estimated by XTT assay ${ }^{18}$ after 3 days of incubation. Based on XTT response and optimization, the VN-MCC cell line and the HaCaT cell line were plated at 2500 cells/well while the VP-MCC cell line was plated at 15,000 cells/well for screening. Pure compound libraries were assessed at 1 and $10 \mu \mathrm{M}$ and natural product extracts (prefractionated and crude) at 1 and $10 \mu \mathrm{g} / \mathrm{ml}$ for their ability to inhibit growth. In total, more than 45,000 samples from a variety of sources were screened. For initial assay development and hit follow-up studies, active growth inhibitory/cytotoxic samples were assessed in a dose-response format using the Promega CellTiter Glo Assay according to the manufacturer's protocol using 2500 cell/well for all cell lines.

Choice of cell lines and control compounds for assay development. Several virus negative (VNMCC) and virus positive (VP-MCC) cell lines have been established and characterized. Among the most widely used VN-MCC cell lines are MCC13, MCC26, and UISO while commonly used VP-MCC cells include MKL-1, MKL-2, and WaGa. These cell lines along with an immortalized human skin cell line (HaCaT) were chosen for preliminary development. For assay development control compounds, navitoclax, pluripotin, and bortezomib were used for assessing differential and general cell killing based on prior experience with these cell lines. Navitoclax (ABT-263) modulates BCL-2 family proteins and was reported to induce cell death in MCC cells ${ }^{19}$. Similarly, bortezomib has been reported to induce cell death in MCC cells at low nanomolar concentrations ${ }^{20}$. An additional control compound, pluripotin was chosen based on reported MCC expression profiles. Pluripotin (SC-1) is an inhibitor of RasGAP, ERK, and S6 kinase ${ }^{21,22}$ and a proteomic study suggested involvement of S6 kinase in $\mathrm{MCC}^{23}$.

Isolation and characterization of natural products. Sources and isolation and identification of natural products from active extracts are described in the Supplementary Information section.

Data analysis. All XTT- and CellTiterGlo-derived cell numbers were normalized to untreated (DMSO only) controls on the same plates. Dose-response curves (during assay development and hit confirmation) were 
a

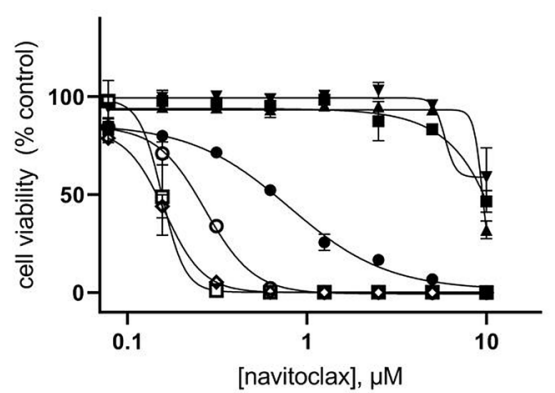

b

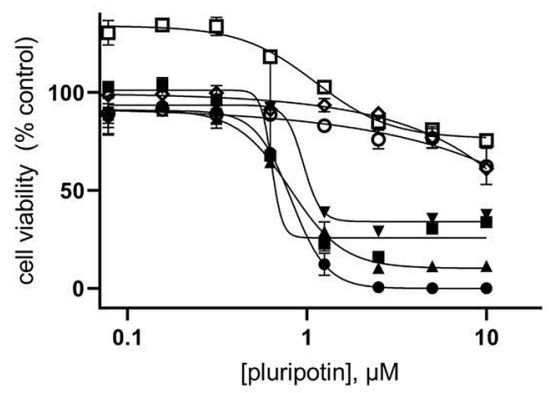

C

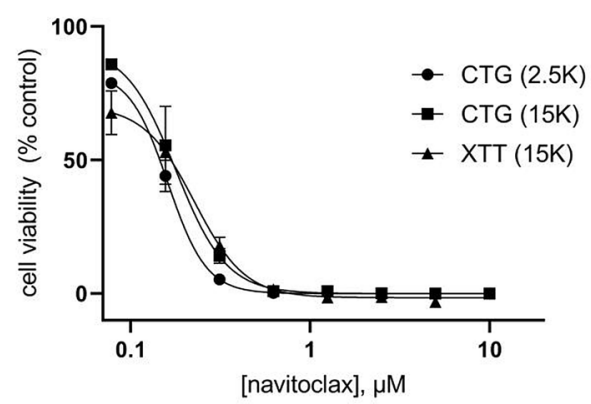

d

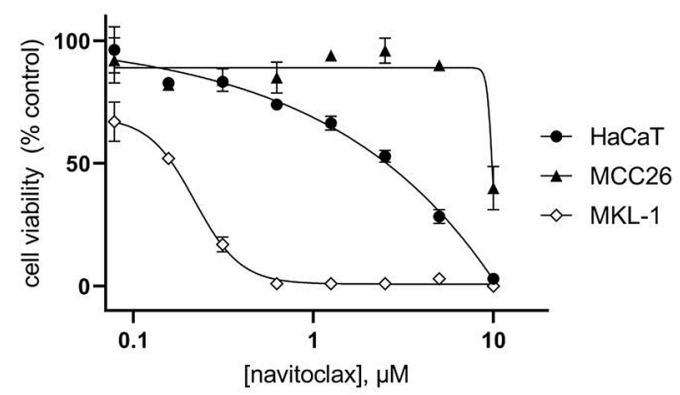

Figure 1. Effects of control compounds on cell survival. The indicated cell lines ( 2500 cells/well, 384-well plates) were incubated for three days with (a) navitoclax (ABT-263), or (b) pluripotin (SC-1) and cell viability was estimated using CellTiterGlo (CTG). In a separate experiment, (c) MKL-1 cells at 2500 or 15,000 cells/well as indicated were treated with navitoclax and cell viability was estimated with XTT or CTG as indicated. (d) XTT assessment of HACAT (2500 cells/well), MCC26 (2500), or MKL-1 $(15,000)$ after navitoclax treatment. In all cases, values were normalized to DMSO controls for each cell line. Error bars represent sd $(n=4)$.

graphed and $\mathrm{IC}_{50}$ values estimated using GraphPad Prism 8 (Graphpad Software, San Diego CA, USA, https:// www.graphpad.com/scientific-software/prism/) 4-parameter logistic nonlinear regression analysis. 'Hit' identification was based on inhibition of MCC cells as discussed in the Results and Discussion sections. For further analysis and comparisons of active compounds, the $\mathrm{Log}$ of the $\mathrm{IC}_{50}$ was determined in Excel and used to generate a heatmap in $\mathrm{R}$ using the gplots, RColorBrewer and colorspace packages.

\section{Results}

Activity of control compounds against MCC cell lines. Navitoclax showed significantly higher potency against VP-MCC cell lines with minimal effects on VN-MCC cells and an intermediate potency against HaCaT cells (Fig. 1A). By contrast, pluripotin preferentially affected VN-MCC and HaCaT cells with little effect on the viability of VP-MCC cells (Fig. 1B). Bortezomib potently eliminated viable cells in all six MCC cell lines and $\mathrm{HaCaT}$-average $\mathrm{IC}_{50} 11 \mathrm{nM}$ (data not shown). To expedite screening and decrease complexity of data analysis, three cell lines were chosen for development of the primary screen: MCC26, MKL-1, and HaCaT. For ease of comparison of results to previous cytotoxicity/growth inhibition assays in the lab, an XTT-based assay ${ }^{18}$ rather than CellTiterGlo was selected for high-throughput application. A much higher cell number (15,000 cells/ well) was required to obtain a reliable XTT signal for MKL-1 cells (data not shown). Navitoclax was therefore used to confirm that the higher cell number was not detrimental to the proposed screening assay configuration. As shown in Fig. 1C, the navitoclax effect on MKL-1 cells was the same whether cell survival was assessed by XTT (at 15,000 cells/well) or CellTiterGlo (at 2500 or 15,000 cells/well). IC 50 for navitoclax on MKL-1 cells was $200 \pm 29 \mathrm{nM}$ (ave $\pm \mathrm{sd}$ ) for the curves shown in Fig. 1. Similarly, XTT analysis of the effects of navitoclax on the other cell lines used in the screening (Fig. 1D) were comparable to those obtained with CellTiterGlo.

Assay development/optimization/repeatability. Cell densities and incubation times were re-assessed for optimization of the XTT assay for MCC26, MKL-1, and HaCaT cells. Supporting Information Figure S1 shows the effect of variation of both cell numbers and incubation times on XTT signals. For HaCaT and MCC26 cells, 2500 cells/well is within the linear range after 1-3 day incubation and signal to background ratio is maximized at 3 days. For MKL-1, signal at 15,000 cells/well is also in the linear range at 3 days, but maximal at 4 days. However, MKL-1 response to navitoclax treatment was considerably more variable at 4 days (Fig. S1). Based on these results, a 3 day treatment time was chosen for the HTS.

The LOPAC 1280 compound library was used to assess assay repeatability and to determine test concentrations and hit definitions. The assay was run multiple times over several days at 1 and $10 \mu \mathrm{M}$. Scatter plots of the average responses of each cell line to each compound are shown in Supporting Information Fig. S2. The coefficient of variation (CV) ranged from 10 to $27 \%$ depending on cell line and concentration. The average $Z^{\prime}$-factor, 


\begin{tabular}{|c|c|c|c|c|c|}
\hline \multirow[b]{2}{*}{ Cells } & \multicolumn{2}{|c|}{ CV (individual compounds) ${ }^{\mathrm{a}}$} & \multicolumn{2}{|c|}{ CV (plate average values) ${ }^{b}$} & \multirow[t]{2}{*}{ Average $Z^{\prime c}$} \\
\hline & $1 \mu \mathrm{M}$ & $10 \mu \mathrm{M}$ & $1 \mu \mathrm{M}$ & $10 \mu \mathrm{M}$ & \\
\hline $\mathrm{HaCaT}$ & 10.9 & 15.4 & 4.1 & 4.8 & 0.71 \\
\hline MCC26 & 18.5 & 20.6 & 10.8 & 11.3 & 0.61 \\
\hline MKL-1 & 17.1 & 27.0 & 3.2 & 13.5 & 0.60 \\
\hline
\end{tabular}

Table 1. Assay reproducibility—repeat assays with LOPAC compounds. CV $=$ sd/average $\times 100 \%$. ${ }^{a}$ average CV for each of 1280 compounds ( $n=3$ repeats per cell line). ${ }^{b}$ average $C V$ for mean plate response $(n=3$ repeats per cell line). ${ }^{c}$ Average $Z^{\prime}, \mathrm{n}=24$ plates per cell line (LOPAC only).

\begin{tabular}{|c|c|c|}
\hline & Pure compounds & Natural product extracts \\
\hline Total screened & 27,753 & 20,532 \\
\hline Primary hits $^{\mathrm{a}}$ & 1214 & 279 \\
\hline $\mathrm{IC}_{50}<10 \mu \mathrm{M}$ or $10 \mu \mathrm{g} / \mathrm{ml}(\mathrm{XTT})^{\mathrm{b}}$ & 93 & 103 \\
\hline $\mathrm{IC}_{50}<1-2 \mu \mathrm{M}$ or $10 \mu \mathrm{g} / \mathrm{ml}(\mathrm{CTG})^{\mathrm{c}}$ & 36 & 55 \\
\hline 7 cell lines $^{\mathrm{d}}$ & 21 & 45 \\
\hline
\end{tabular}

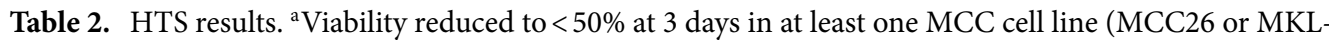
1) and no general toxicity using 1 or $10 \mu \mathrm{M}$ of pure compounds, 1 or $10 \mu \mathrm{g} / \mathrm{ml}$ of natural product extracts. ${ }^{\mathrm{b}} \mathrm{IC}_{50}<10 \mu \mathrm{M}$ with 5-point dose response curve. ${ }^{\mathrm{c}} \mathrm{IC}_{50}<2 \mu \mathrm{M}$ with 10 -point dose response curve. ${ }^{\mathrm{d}}$ Tested across 6 MCC cell lines plus HaCaT control cells. For natural product extracts, confirmed active samples were those that maintained a differential effect in each of the sequential steps.

a measure of assay quality ${ }^{24}$, for each cell line is above 0.6 indicating a good assay window under the optimized screening conditions. Z' was calculated for all assay plates to monitor assay performance throughout the screening campaign. Reproducibility for repeats of individual samples and across the plates is detailed in Table 1 for each cell line. Active compounds (i.e., $<50 \%$ cell survival at 1 and/or $10 \mu \mathrm{M})$ for each cell line were re-assessed in dose-response format for confirmation.

Application to high throughput screening. To maximize the probability of identifying samples with interesting activities against MCC cells, an increasingly stringent sequential assay process was defined. Primary screening was performed by treating MCC26, MKL-1, and HaCaT cells at 1 and $10 \mu \mathrm{M}$ (or 1 and $10 \mu \mathrm{g} / \mathrm{ml}$ for natural product extracts) for 3 days. Samples that reduced cell survival to $<50 \%$ of control for one or both MCC cell lines at either concentration were considered as primary hits. Samples that affected all three cell lines at both concentrations were considered to be generally toxic and not further pursued. Primary hits were then assessed in a dose-response formats, first using XTT in a 5-point 1:2 dilution series (10-20 $\mu \mathrm{M}$ starting concentration for compounds, $10-20 \mu \mathrm{g} / \mathrm{ml}$ for natural product extracts). Agents with an $\mathrm{IC}_{50}<10 \mu \mathrm{M}$ were then tested with a 10-point 1:2 dilution series (starting concentration typically $10 \mu \mathrm{M}$ or $10-20 \mu \mathrm{g} / \mathrm{ml}$ ) using CellTiterGlo. An $\mathrm{IC}_{50}$ less than $2 \mu \mathrm{M}$ (or $10 \mu \mathrm{g} / \mathrm{ml}$ for extracts) in this assay was considered active. Finally, in order to corroborate selectivity, remaining active samples were assessed in 10-point 1:2 dilution series with CellTiterGlo for the seven cell lines discussed above. In the CellTiterGlo experiments, all cells were assessed at 2500 cells/well (see Table 2 for screening statistics). The numbers in the table indicate samples that continued to exhibit potent effects when assessed against all 7 cell lines which comprised the majority of the active samples. However, a few samples (for example, tonantzitlolone and caulibugulone B - see Supporting Information Fig. S3) appeared to have selective activity when three cell lines were assessed, but actually only had activity against a single cell line once all seven were assessed.

Active compounds identified by high-throughput screening. A total of 21 known compounds were available from commercial sources or from the National Cancer Institute Developmental Therapeutics Program and showed significant differential activities across seven cell lines. Figure 2 gives a visual representation of the potency $\left[\log \left(\mathrm{IC}_{50}\right)\right]$ against the 7 cell lines tested of each of the active compounds from the screen along with navitoclax and pluripotin. Complete dose-response curves and structures are provided in Supporting Information (Fig. S4). The majority of the hit compounds had selectivity for VP-MCC cells which was defined as having an average $\mathrm{IC}_{50}<50 \%$ of the VN-MCC average $\mathrm{IC}_{50}$. Two compounds, cladribine and NSC175493 were inactive against MCC26, but active against all of the other MCC lines. Etoposide potently reduced viability of MCC13, but not the other VN-MCC cells and was active against all of the VP-MCC cell lines. Borrelidin appeared to have some specificity for VN-MCC cells but $\mathrm{IC}_{50}$ values could not be calculated for VP-MCC cells (see Fig. S4). Cladribine, disulfiram, englerin A, gloxazone, NSC185065, and pyrrolidinedithiocarbamate were similarly effective for VN-MCC and VP-MCC cell lines. With two exceptions (clofarabine and thapsigargin), all of the compounds had $\mathrm{IC}_{50}$ values that were on average fivefold lower against VN-MCC and/or VP-MCC as compared to HaCaT cells. 


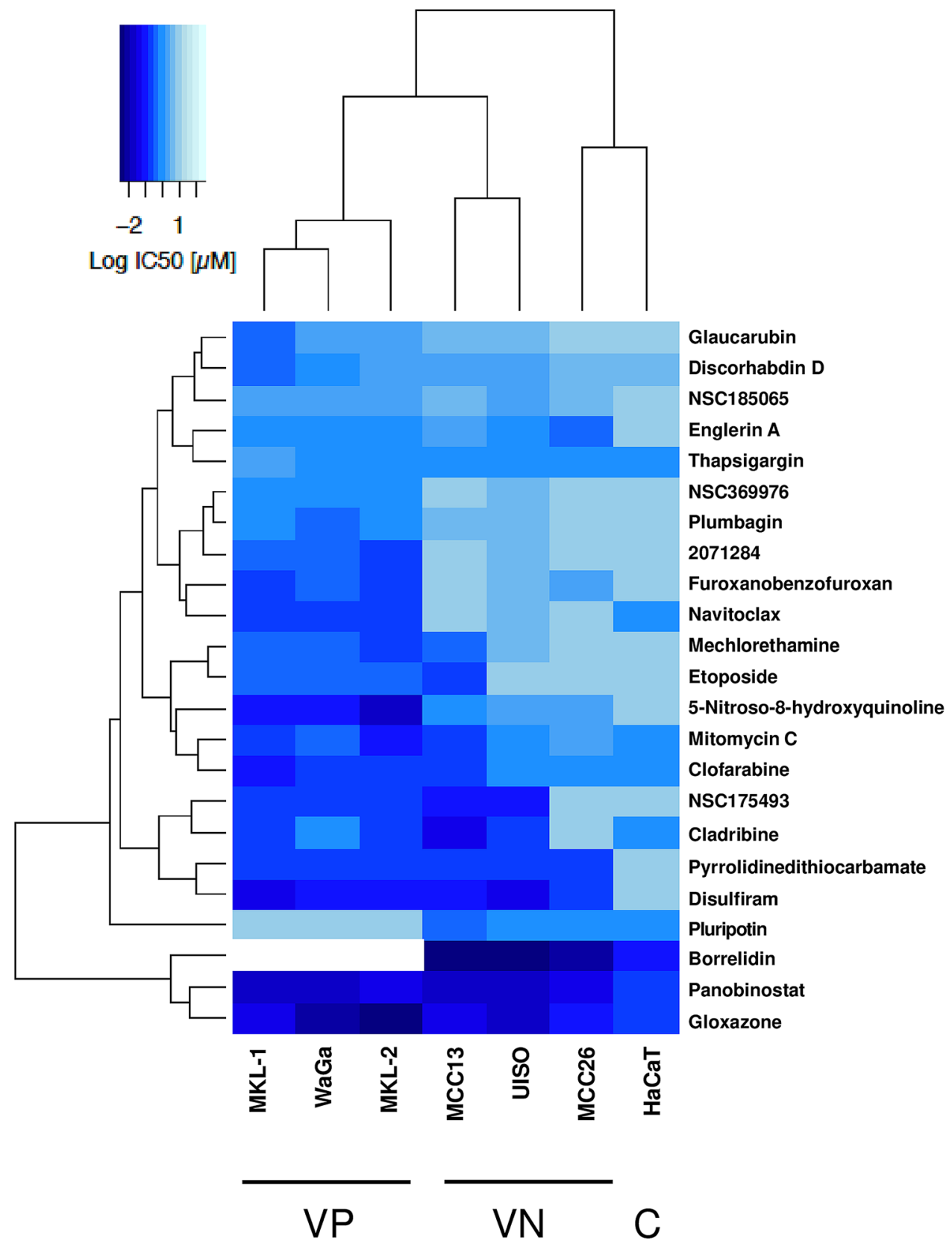

Figure 2. Visualization of drug effectiveness in MCC and control cell lines. VP-MCC, VN-MCC and HaCaT (control) cells were treated with 23 compounds for $72 \mathrm{~h}$. CellTiter Glo assay was used to measure cell viability and determine the $\mathrm{IC}_{50}$ for each compound. The log of the $\mathrm{IC}_{50}$ was determined and visualized in a heatmap generated in R version 1.3.1073 (R Core Team (2013). R: A language and environment for statistical computing. R Foundation for Statistical Computing, Vienna, Austria. http://www.R-project.org/). Dendrograms indicate cell line and compound similarities based on unsupervised hierarchical clustering. Darker shades indicate higher potency. For borrelidin, $\mathrm{IC}_{50}$ could not be calculated (white region) for VP-MCC lines (see Supplementary Figure S4 for dose-response curves for all compounds and cell lines).

Natural product extracts and derived compounds. As seen in Table 2, 45 natural product extracts were active and maintained differential activity when assessed against the 7 -cell line panel. These extracts consist of potentially complex mixtures of metabolites from each source organisms. Three active natural product extracts were further assessed. In each case, the extracts had significant effects on multiple MCC cell lines and minimal effects on the $\mathrm{HaCaT}$ control cell line. As described in Supplementary Information, these extracts were subjected to assay-guided fractionation to purify and identify active components. Processing of each extract yielded a pure compound with differential activity in the 7-cell line panel. Figure 3 shows these results, includ- 
a
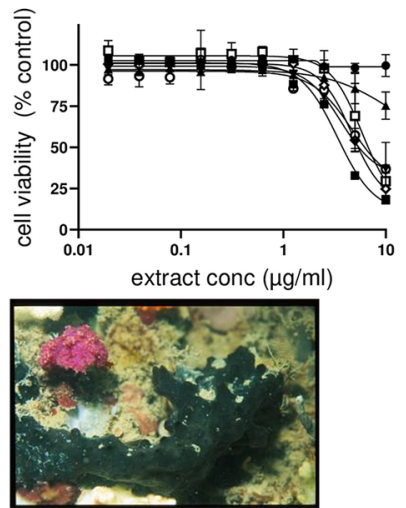

Acanthostrongylophora sp

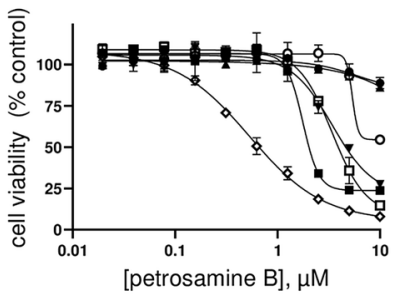

$\bullet \mathrm{HaCaT}$

- MCC13

$\mp \mathrm{MCC} 26$

$\rightarrow$ UISO

$\diamond \mathrm{MKL}-1$

- $M K L-2$

- - WaGa

$\begin{array}{ll}\text { Cells } & \mu \mathrm{M} \mathrm{IC}_{50}(95 \% \mathrm{Cl}) \\ \text { HaCaT } & >10 \\ \text { MCC13 } & 1.76(1.58-1.95) \\ \text { MCC26 } & >10 \\ \text { UISO } & 3.14(2.70-5.00) \\ \text { MKL-1 } & 0.53(0.47-0.61) \\ \text { MKL-2 } & >10 \\ \text { Waga } & 3.40(3.08-3.82)\end{array}$

petrosamine $\mathrm{B}$<smiles>C[N+]1=Cc2c(O)c3nc4ccc(Br)cc4c4c(=O)[n+](C)ccc(c2=C1)c34</smiles>

b

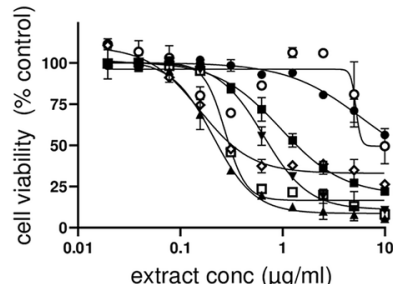

extract conc $(\mu \mathrm{g} / \mathrm{ml})$

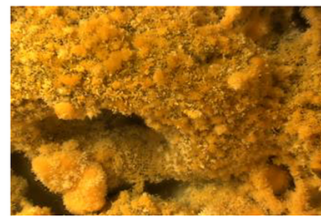

Clonostachys rosea isolate (Ml4762 TV8-1)

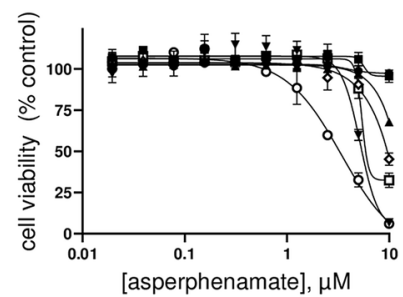

asperphenamate

$$
\begin{aligned}
& \text { - HaCaT } \\
& \text { - MCC13 } \\
& \text { - MCC26 } \\
& \text { - UISO } \\
& \text { क MKL-1 } \\
& \text { - MKL-2 } \\
& \text { - WaGa }
\end{aligned}
$$

$\begin{array}{ll}\underline{\text { Cells }} & \mu \mathrm{M} \mathrm{IC}_{50}(95 \% \mathrm{Cl}) \\ \text { HaCaT } & >10 \\ \text { MCC13 } & >10 \\ \text { MCC26 } & >10 \\ \text { UISO } & 5.19(4.7-7.44) \\ \text { MKL-1 } & \sim 10 \\ \text { MKL-2 } & 3.41(2.51-6.68) \\ \text { WaGa } & \sim 5\end{array}$

WaGa $\sim 5$<smiles>O=C(NC(COC(=O)c1ccccc1)Cc1ccccc1)NC(Cc1ccccc1)C(=O)c1ccccc1</smiles>
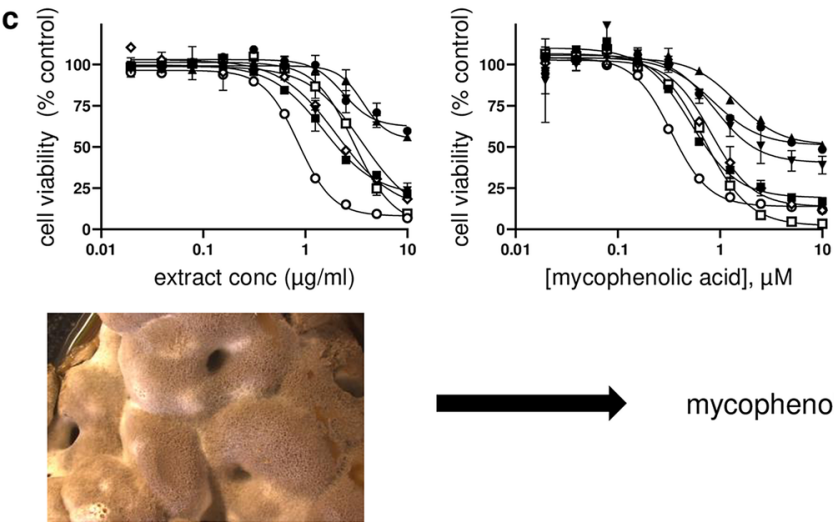

mycophenolic acid

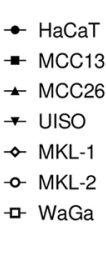

$\begin{array}{ll}\text { Cells } & \underline{\mu \mathrm{M} \mathrm{IC}} \underline{50}_{50}(95 \% \mathrm{Cl}) \\ \text { HaCaT } & \sim 5 \\ \text { MCC13 } & 0.51(0.45-0.58) \\ \text { MCC26 } & 1.4 \\ \text { UISO } & \sim 5 \\ \text { MKL-1 } & 0.82(0.70-0.98) \\ \text { MKL-2 } & 0.33(0.31-0.36) \\ \text { WaGa } & 0.70(0.64-0.76)\end{array}$<smiles>COc1c(C)c2c(c(O)c1C/C=C(\C)CCC(=O)O)C(=O)OC2</smiles>

Penicillium sp. isolate (23 BIA-6)

Figure 3. Natural product extracts and derived active compounds. Natural product extracts that reduced MCC cell viability were assessed for activity against the 7 cell lines discussed in the text (left graph in each panel). Pure compounds obtained from these extracts were similarly assessed for activity and $\mathrm{IC}_{50}$ values calculated via GraphPad Prism software (right graph and table in each panel). Source organisms and compound isolation and structure elucidation are further discussed in Supplementary Information. Photograph of Acanthostrongylophora sp. taken by the Coral Reef Research Foundation under contract to (and provided by) the Natural Products Branch of the National Cancer Institute. Photos of the fungi (Clonostachys rosea and Penicillium sp.) were obtained the University of Oklahoma. Compound structures were obtained from the PubChem database. 


\begin{tabular}{|l|l|l|l|}
\hline Compound (NSC\#) & Selectivity $^{\mathrm{a}}$ & Target/MOA & References \\
\hline 5-Nitroso-8-quinolinol (3852) & VP & HDAC inhib/ROS active & 41 \\
\hline Panobinostat (761190) & VP & HDAC inhib/ROS active & 46 \\
\hline Plumbagin (688284) & VP & ROS/redox-active, proteasome & 47,48 \\
\hline Mechlorethamine (762) & VP & DNA damage & 49 \\
\hline Mitomycin C (26980) & VP & DNA damage & 50 \\
\hline Etoposide (141540) & VP & topo II/DNA damage & 51 \\
\hline Gloxazone (82116) & Non & DNA synthesis inhib & 52 \\
\hline Cladribine (105014) & Non & DNA synthesis inhib & 53 \\
\hline Clofarabine (606869) & Non & DNA synthesis inhib & 54 \\
\hline Glaucarubin (14975) & VP & protein synthesis inhib & 55 \\
\hline Borrelidin (216128) & Uncertain ${ }^{\mathrm{b}}$ & ptn synth/tRNA synthesis inhib $^{5}$ & 56 \\
\hline Disulfiram (756748) & Non & NFkB, ROS, proteasome & 28,38 \\
\hline Pyrrolidine dithiocarbamate (298194) & Non & NFkB, ROS, proteasome & 29,31 \\
\hline Furoxanobenzofuroxan (228139) & VP & Monoamine oxidase inhib $^{5}$ & 57 \\
\hline Thapsigargin (299933) & Non?c & Ca $^{2+} /$ ER stress & 58 \\
\hline Englerin A (141540) & Non & PKC/Ca $^{2+}$ & 59 \\
\hline
\end{tabular}

Table 3. Active compounds with putative known targets or mechanisms of action. ${ }^{a}$ Based on average $\mathrm{IC}_{50}$ for $\mathrm{VP}$ and VN cell lines. ${ }^{\mathrm{b}} \mathrm{IC}_{50}$ could not be calculated for VP cell lines. ${ }^{\mathrm{c} I n c o m p l e t e ~ l o s s ~ o f ~ c e l l ~ v i a b i l i t y ~ a t ~ h i g h e s t ~}$ concentrations.

ing the identity of the extracts and structures of the natural products (petrosamine $B$, asperphenamate, and mycophenolic acid). These compounds were not represented in the pure compound HTS screening libraries.

\section{Discussion}

A multi-tiered high-throughput viability screen successfully identified substances able to selectively target Merkel cell carcinoma cells in general or based on virus status. Many agents that inhibited MCC cell viability also affected control cells with most demonstrating toxicity against all three cell lines at the two doses tested in the initial screen. Samples able to affect one or two of the MCC screening cell lines were reassayed in dose-response format with an orthogonal cell viability assay followed by assessment of activity against two additional VNMCC and two additional VP-MCC cell lines. Reliance of the screening assay on three cell lines sometimes led to samples that specifically affected only one of the screening lines without subsequent effects on the other MCC cells in the same class (see Supplementary Fig. S3). VN-MCC tumors are reported to be more heterogeneous and have higher mutational burdens than VP-MCC tumors ${ }^{3}$. It is therefore not surprising that the screen identified significantly more compounds with variable effects on VN-MCC cell lines than on VP-MCC cells (Fig. 2 and Fig. S3). In particular, there were VN-MCC outlier cell line responses to cladribine, clofarabine, englerin A, furanobenzofuroxan, mechlorethamine, mitomycin C, and NSC175493.

The majority of compounds identified were selective for VP-MCC cells with only a few showing apparent VN-MCC specificity. Among the 21 active pure compounds identified, 16 have previously been reported to modulate specific molecular targets and/or operate via specific mechanisms of action (in addition, the compound designated 2071284 is an analog of furoxanobenzofuraxan and presumably has a similar MOA). Table 3 lists these compounds sorted by reported mechanism and/or molecular targets. Two of these compounds have been used with MCC in pre-clinical or clinical applications, albeit in combination therapy (etoposide ${ }^{5}$ ) or for sensitization to immunotherapy (panobinostat ${ }^{25}$ ). Panobinostat's efficacy in immunotherapy for MCC is apparently due to it activity as an HDAC inhibitor ${ }^{25,26}$. Another compound with reported HDAC inhibitory activity, 5-nitroso8-quinolinol was also found in this screen. Although these compounds also have other activities, their presence among the MCC-active compounds identified suggests that HDAC inhibition may not only augment immunotherapy, but may also directly affect the cells. Several compounds including dischorhabdin D, NSC175493, NSC185065, and NSC369976 either apparently are absent from the literature or are simply noted as growth inhibitory/cytotoxic against some cell lines, although NSC175493 may induce DNA damage ${ }^{27}$.

A number of potential MCC targets and pathways including PI3K/mTOR/AKT, receptor tyrosine kinases and downstream signaling, DNA repair, survivin, BCL-2 family, HDACs, heat shock proteins, MDM2, etc. have been suggested in the literature (see ${ }^{1,3}$ for recent reviews). Many of the compounds identified in this screen have been reported to directly or indirectly affect one or more of these pathways. As seen in Table 3, MCC-selective cell killing can be induced by agents reported to affect a variety of cellular mechanisms, including generation of reactive oxygen species (ROS) and redox effects, effects on DNA synthesis, damage, and repair, inhibition of HDACs, inhibition of protein synthesis, etc. Disulfiram and pyrrolidinedithiocarbamate (PDTC), both NFkB inhibitors ${ }^{28,29}$, are among the most potent compounds identified. However, it has also been shown that disulfiram can affect other cellular processes including proteasomal degradation of proteins and ROS generation ${ }^{30}$. Similarly, PDTC is generally identified as an NFKB inhibitor, but has also been reported to affect proteasomal activity and, depending on conditions, act as a pro- or anti-oxidant ${ }^{31,32}$. MCV polyoma virus small T antigen has variously been reported to inhibit ${ }^{33}$ or activate $^{34}$ canonical $\mathrm{NF \kappa B}$ or to activate non-canonical $\mathrm{NF \kappa B}^{35}$. Effects of 
both PDTC and disulfiram were equipotent against VP-MCC and VN-MCC cells and may be due to their other targets. Five compounds were found to be highly VP-MCC-selective ( $>$ fivefold based on average $\mathrm{IC}_{50}$ values) with no effect on $\mathrm{HaCaT}$ control cells (up to $10 \mu \mathrm{M}$ ) and without significant outlier cell line effects. All five also had sub $\mu \mathrm{M}$ potency against VP-MCC cell lines. These were furoxanobenzofuroxan and its analog 2071284, 5-nitroso-8-hydroxyquinoline, plumbagin, and NSC369976. The only target identified for furoxanobenzofuroxan (and by extension its analog) is monoamine oxidase. Although no clear connection to MCC appears in the literature, monoamine oxidase may be highly expressed in Merkel cells ${ }^{36}$. As seen in Table 3, other targets of active compounds include ROS, HDACs, DNA and protein synthesis, and DNA damage. Although generally considered to be a protein synthesis inhibitor, glaucarubin was reported to induce DNA damage leading to its VP-MCC-selective effects in a previous screen ${ }^{10}$. There were several compounds for which no cellular mechanisms or molecular targets could be found in the literature and a number of those with putative mechanisms have apparently not been extensively studied, in some cases for decades.

Zinc and/or copper binding have been implicated in the activities of several of the compounds identified in this study. These include pyrrolidine dithiocarbamate ${ }^{31,37}$, disulfiram ${ }^{38}$, clofarabine and cladribine ${ }^{39}$, gloxazone [(3-ethoxy-2-oxobutyraldehyde bis(thiosemicarbazone) $]^{40}$, and 5-nitroso-8-quinolinol ${ }^{41}$ suggesting additional potential pathways by which MCC may be attacked. Interestingly, these clustered in the lower half of the heat map shown in Fig. 2.

The plethora of possible mechanisms of action represented by the compounds identified in this screening campaign suggests a potentially wide variety of mechanisms by which MCC cells can be targeted. Many of these compounds, in fact, have multiple reported mechanisms and may require effects on multiple cellular processes to modulate MCC cell growth and survival. Similarly, there was no clear correlation between structural features of active compounds and their potency or selectivity. It is of particular interest that a significant number of the pure compounds identified in the screen are natural products. In fact, several natural products have been reported to have potentially useful activity against MCC cells ${ }^{10,11}$. As a result, a small library of crude or partially purified natural product extracts was also screened yielding active extracts from 45 organisms. These are undergoing assay-guided fractionation to purify and characterize potentially novel modulators of MCC cell growth. Three derived compounds are described here. Mycophenolic acid is an extensively characterized drug with a range of cancer-relevant molecular targets and mechanisms ${ }^{42}$ and asperphenamate is reported to be a cathepsin inhibitor $^{43}$. By contrast, petrosamine B has not been widely studied although it has been reported to inhibit an enzyme from $H$. pylori ${ }^{44}$. The results of the pure compound screen demonstrate that HTS assay was effective in identifying active small molecules with effects consistent with their known MCC-relevant mechanisms of action and/or molecular targets, including some of which have previously shown promise as MCC-targeted agents. Further analysis of new natural products and compounds without known mechanisms of action may reveal additional possible avenues for targeting MCC cells. A range of targets have been reported for several of the individual compounds identified in this study and polypharmacology is often a feature of natural products ${ }^{45}$. Thus, further investigation of natural products may be a particularly fruitful approach for the identification of novel therapeutics and probes. Interestingly, like the sources of mycophenolic acid and asperphenamate, the majority of the MCC-active natural product extracts are from fungal samples sourced via the Citizen Science Soil Collection Program at the University of Oklahoma ${ }^{60}$. From the discovery of penicillin onward, fungi have been rich sources of novel biologically active natural products ${ }^{61}$.

Received: 11 May 2021; Accepted: 21 June 2021

Published online: 30 June 2021

\section{References}

1. Cohen, L. \& Tsai, K. Y. Molecular and immune targets for Merkel cell carcinoma therapy and prevention. Mol. Carcinog. 58, 1602-1611 (2019).

2. Agelli, M., Clegg, L. X., Becker, J. C. \& Rollison, D. E. The etiology and epidemiology of Merkel cell carcinoma. Curr. Probl. Cancer. 34, 14-37 (2010).

3. Harms, P. W. et al. The biology and treatment of Merkel cell carcinoma: Current understanding and research priorities. Nat. Rev. Clin. Oncol. 15, 763-776 (2018).

4. Banks, P. D., Sandhu, S., Gyorki, D. E., Johnston, M. L. \& Rischin, D. Recent insights and advances in the management of Merkel cell carcinoma. J. Oncol. Pract. 12, 637-646 (2016).

5. Poulsen, M. et al. High-risk Merkel cell carcinoma of the skin treated with synchronous carboplatin/etoposide and radiation: A Trans-Tasman Radiation Oncology Group Study-TROG 96:07. J. Clin. Oncol. 21, 4371-4376 (2003).

6. Samimi, M. Immune checkpoint inhibitors and beyond: an overview of immune-based therapies in Merkel cell carcinoma. Am. J. Clin. Dermatol. 20, 391-407 (2019).

7. Tothill, R., Estall, V. \& Rischin, D. Merkel cell carcinoma: Emerging biology, current approaches, and future directions. Am. Soc. Clin. Oncol. Educ. Book. 2015, e519-526 (2015).

8. Harvey, A. L. Natural products in drug discovery. Drug Discov. Today. 13, 894-901 (2008).

9. Newman, D. J. \& Cragg, G. M. Natural products as sources of new drugs over the nearly four decades from $01 / 1981$ to $09 / 2019$. J. Nat. Prod. 83, 770-803 (2020).

10. Liu, W., Krump, N. A., Herlyn, M. \& You, J. Combining DNA damage induction with BCL-2 inhibition to enhance Merkel cell carcinoma cytotoxicity. Biology 9, 35 (2020).

11. Chamcheu, J. C. et al. Role and therapeutic targeting of the PI3K/Akt/mTOR signaling pathway in skin cancer: A review of current status and future trends on natural and synthetic agents therapy. Cells 8, E803 (2019).

12. Leonard, J. H., Dash, P., Holland, P., Kearsley, J. H. \& Bell, J. R. Characterisation of four Merkel cell carcinoma adherent cell lines. Int. J. Cancer. 60, 100-107 (1995).

13. Ronan, S. G., Green, A. D., Shilkaitis, A., Huang, T. S. \& Das Gupta, T. K. Merkel cell carcinoma: In vitro and in vivo characteristics of a new cell line. J. Am. Acad. Dermatol. 29, 715-722 (1993).

14. Rosen, S. T. et al. Establishment and characterization of a neuroendocrine skin carcinoma cell line. Lab Invest. 56, 302-312 (1987). 
15. Martin, E. M. et al. Parathyroid hormone-related protein, chromogranin A, and calcitonin gene products in the neuroendocrine skin carcinoma cell lines MKL1 and MKL2. Bone Miner. 14, 113-120 (1991).

16. Houben, R. et al. Merkel cell polyomavirus-infected Merkel cell carcinoma cells require expression of viral T antigens. J. Virol. 84, 7064-7072 (2010).

17. Boukamp, P. et al. Normal kerotinization in a spontaneously immortalized aneuploid human keratinocyte cell line. J. Cell Biol. 106, 761-771 (1988)

18. Scudiero, D. A. et al. Evaluation of a soluble tetrazolium/formazan assay for cell growth and drug sensitivity in culture using human and other tumor cell lines. Cancer Res. 48, 4827-4833 (1988).

19. Verhaegen, M. E. et al. Merkel cell carcinoma dependence on bcl-2 family members for survival. J. Invest. Dermatol. 134, 2241-2250 (2014).

20. Arora, R. et al. Survivin is a therapeutic target in Merkel cell carcinoma. Sci. Transl. Med. 4, 13356 (2012).

21. Mertins, S. D. et al. A small molecule (pluripotin) as a tool for studying cancer stem cell biology: Proof of concept. PLoS ONE 8 , E57099 (2013)

22. Li, W., Li, K., Wei, W. \& Ding, S. Chemical approaches to stem cell biology and therapeutics. Cell Stem Cell 13, 270-283 (2013).

23. Shao, Q. et al. A proteomic study of human Merkel cell carcinoma. J. Proteom. Bioinform. 6, 275-282 (2013).

24. Zhang, J. H., Chung, T. D. \& Oldenburg, K. R. A simple statistical parameter for use in evaluation and validation of high throughput screening assays. J. Biomol. Screen. 4, 67-73 (1999).

25. Ugurel, S. et al. MHC class-I downregulation in PD-1/PD-L1 inhibitor refractory Merkel cell carcinoma and its potential reversal by histone deacetylase inhibition: A case series. Cancer Immunol. Immunother. 68, 983-990 (2019).

26. Ritter, C. et al. Epigenetic priming restores the HLA class-I antigen processing machinery expression in Merkel cell carcinoma. Sci. Rep. 7, 2290 (2017).

27. Hasinoff, B. B. et al. Cellular mechanisms of the cytotoxicity of the anticancer drug elesclomol and its complex with $\mathrm{Cu}(\mathrm{II})$. Biochem. Pharmacol. 93, 266-276 (2015).

28. Liu, G. Y., Frank, N., Bartsch, H. \& Lin, J. K. Induction of apoptosis by thiuramdisulfides, the reactive metabolites of dithiocarbamates, through coordinative modulation of NFkappaB, c-fos/c-jun, and p53 proteins. Mol. Carcinog. 22, 235-246 (1998).

29. Schreck, R., Meier, B., Männel, D. N., Dröge, W. \& Baeuerle, P. A. Dithiocarbamates as potent inhibitors of nuclear factor kappa B activation in intact cells. J. Exp. Med. 175, 1181-1194 (1992).

30. Yang, Q. et al. An updated review of Disulfiram: Molecular targets and strategies for cancer treatment. Curr. Pharm. Des. 25, 3248-3256 (2019)

31. Chung, K. C. et al. Novel biphasic effect of pyrrolidine dithiocarbamate on neuronal cell viability is mediated by the differential regulation of intracellular zinc and copper ion levels, NF-kappaB, and MAP kinases. J. Neurosci Res. 59, 117-125 (2000).

32. Lee, E. H., Kim, S. S. \& Seo, S. R. Pyrrolidine dithiocarbamate (PDTC) inhibits inflammatory signaling via expression of regulator of calcineurin activity 1 (RCAN1): Anti-inflammatory mechanism of PDTC through RCAN1 induction. Biochem. Pharmacol. 143, 107-117 (2017)

33. Griffiths, D. A. et al. Merkel cell polyomavirus small T antigen targets the NEMO adaptor protein to disrupt inflammatory signaling. J. Virol. 87, 13853-13867 (2013).

34. Berrios, C. et al. Merkel cell polyomavirus small $\mathrm{T}$ antigen promotes pro-glycolytic metabolic perturbations required for transformation. PLoS Pathog. 12, e1006020 (2016).

35. Zhao, J. et al. Merkel cell polyomavirus small T antigen activates noncanonical NFkB signaling to promote tumorigenesis. Mol. Cancer Res. 18, 1623-1637 (2020).

36. Vitalis, T. et al. Developmental expression pattern of monoamine oxidases in sensory organs and neural crest derivatives. J. Comp. Neurol. 464, 392-403 (2003).

37. Kim, I. et al. Pyrrolidine dithiocarbamate and zinc inhibit proteasome-dependent proteolysis. Exp. Cell Res. 298, 229-238 (2004).

38. Jiao, Y., Hannafon, B. N. \& Ding, W. Q. Disulfiram's anticancer activity: Evidence and mechanisms. Anticancer Agents Med. Chem. 16, 1378-1384 (2016).

39. Tsesmetzis, N., Paulin, C. B., Rudd, S. G. \& Herold, N. Nucleobase and nucleoside analogues: Resistance and re-sensitisation at the level of pharmacokinetics, pharmacodynamics and metabolism. Cancers (Basel) 10, 240 (2018).

40. Van Giessen, G. J., Crim, J. A., Petering, D. H. \& Petering, H. G. Effect of heavy metals on the in vitro cytotoxicity of 3-Ethoxy2-Oxobutyraldehyde bis(thiosemicarbazone) and related compounds. J. Natl. Cancer Inst. 51, 139-146 (1973).

41. Martirosyan, A. et al. Actions of a histone deacetylase inhibitor NSC3852 (5-nitroso-8-quinolinol) link reactive oxygen species to cell differentiation and apoptosis in MCF-7 human mammary tumor cells. J. Pharmacol. Exp. Ther. 317, 546-552 (2006).

42. Benjanuwattra, J., Chaiyawat, P., Pruksakorn, D. \& Koonrungsesomboon, N. Therapeutic potential and molecular mechanisms of mycophenolic acid as an anticancer agent. Euro. J. Pharmacol. 887, 173580 (2020).

43. Yuan, L. et al. A novel cathepsin L inhibitor prevents the progression of idiopathic pulmonary fibrosis. Bioorg. Chem. 94, 102417 (2020).

44. Carroll, A. R., Ngo, A., Quinn, R. J., Redburn, J. \& Hooper, J. N. A. Petrosamine B, an inhibitor of the Heliobacter pylori enzyme aspartyl semialdehyde dehydrogenase from the Australian sponge Oceanapia sp. J. Nat. Prod. 68, 804-806 (2005).

45. Ho, T. T., Tran, Q. T. \& Chai, C. L. The polypharmacology of natural products. Future Med. Chem. 10, 1361-1368 (2018).

46. Singh, A. K., Bishayee, A. \& Pandey, A. K. Targeting histone deacetylases with natural and synthetic agents: An emerging anticancer strategy. Nutrients 10, E731 (2018).

47. Tripathi, S. K., Panda, M. \& Biswal, B. K. Emerging role of plumbagin: Cytotoxic potential and pharmaceutical relevance towards cancer therapy. Food Chem. Toxicol. 125, 566-582 (2019).

48. Binoy, A. et al. Plumbagin induces paraptosis in cancer cells by disrupting the sulfhydryl homeostasis and proteasomal function. Chem. Biol. Interact. 310, 108733 (2019) (corrigendum, 311, 108791, 2019).

49. Singh, R. K., Kumar, S., Prasad, D. N. \& Bhardwaj, T. R. Therapeutic journey of nitrogen mustard as alkylating anticancer agents: Historic to future perspectives. Eur. J. Med. Chem. 151, 401-433 (2018).

50. Blasiak, J. DNA-damaging anticancer drugs: A perspective for DNA repair-oriented therapy. Curr. Med. Chem. 24, 1488-1503 (2017).

51. Baldwin, E. L. \& Osheroff, N. Etoposide, topoisomerase II and cancer. Curr. Med. Chem. Anticancer Agents. 5, 363-372 (2005).

52. Booth, B. A., Johns, D. G., Bertino, J. R. \& Sartorelli, A. C. Sites of inhibition of DNA synthesis by kethoxal bis(thiosemicarbazone). Nature 217, 250-251 (1968).

53. Molica, M. et al. The role of cladribine in acute myeloid leukemia: An old drug up to new tricks. Leuk. Lymphoma. 61, 536-545 (2020).

54. Parker, W. B. \& Gandhi, V. Clofarabine: Structure, mechanism of action, and clinical pharmacology. In Chemotherapy for Leukemia: Novel Drugs and Treatments (ed. Ueda, T.) 261-286 (Springer, 2017).

55. Fukamiya, N. et al. Structure-activity relationships of quassinoids for eukaryotic protein synthesis. Cancer Lett. 220, 37-48 (2005).

56. Francklyn, C. S. \& Mullen, P. Progress and challenges in aminoacyl tRNA synthesis-based therapeutics. J. Biol. Chem. 294, 53655385 (2019).

57. Bolt, A. G. \& Sleigh, M. J. Furoxanobenzofuroxan, a selective monoamine oxidase inhibitor. Biochem Pharmacol. 23, 1969-1977 (1974). 
58. Peterkova, L., Kmoníckova, E., Ruml, T. \& Rimpelova, S. Sarco/Endoplasmic reticulum calcium ATPase inhibitors: Beyond anticancer perspective. J. Med. Chem. 63, 1937-1963 (2020).

59. Wu, Z. et al. Englerins: A Comprehensive review. J. Nat. Prod. 80, 771-781 (2017).

60. Du, L. et al. Crowdsourcing natural products discovery to access uncharted dimensions of fungal metabolite diversity. Angew Chem. Int. Ed. Engl. 53, 804-809 (2014) (erratum, 54, 6671, 2015).

61. Bhattarai, K. et al. Fungal natural products galaxy: Biochemistry and molecular genetics toward blockbuster drugs discovery. Adv. Genet. 107, 193-284 (2021).

\section{Acknowledgements}

This project has been funded in whole or in part with federal funds from the National Cancer Institute, National Institutes of Health, under contract HHSN261200800001E. The content of this publication does not necessarily reflect the views or policies of the Department of Health and Human Services, nor does mention of trade names, commercial products or organizations imply endorsement by the US Government. This research was supported (in part) by the Intramural Research Program of the NIH.

\section{Author contributions}

All authors contributed to manuscript preparation and editing. C.J.H. and I.B. contributed to overall study design. E.A.S., N.T.H., T.G., K.A.G., C.J.H. designed and performed experiments. E.A.S., N.T.H., E.I.G., C.J.H., I.B. contributed to data analysis and interpretation. K.L.W. and R.H.C. isolated and characterized fungi and provided extracts. H.R.B., C.-K.K., and K.R.G. isolated and determined structures of natural products.

\section{Funding}

Open Access funding provided by the National Institutes of Health (NIH).

\section{Competing interests}

The authors declare no competing interests.

\section{Additional information}

Supplementary Information The online version contains supplementary material available at https://doi.org/ 10.1038/s41598-021-93097-9.

Correspondence and requests for materials should be addressed to C.J.H.

Reprints and permissions information is available at www.nature.com/reprints.

Publisher's note Springer Nature remains neutral with regard to jurisdictional claims in published maps and institutional affiliations.

Open Access This article is licensed under a Creative Commons Attribution 4.0 International License, which permits use, sharing, adaptation, distribution and reproduction in any medium or format, as long as you give appropriate credit to the original author(s) and the source, provide a link to the Creative Commons licence, and indicate if changes were made. The images or other third party material in this article are included in the article's Creative Commons licence, unless indicated otherwise in a credit line to the material. If material is not included in the article's Creative Commons licence and your intended use is not permitted by statutory regulation or exceeds the permitted use, you will need to obtain permission directly from the copyright holder. To view a copy of this licence, visit http://creativecommons.org/licenses/by/4.0/.

This is a U.S. Government work and not under copyright protection in the US; foreign copyright protection may apply 2021 